\title{
Human Casualties and War: Results of a National Epidemiologic Survey in Iran
}

\author{
Mohammadreza Soroush, MD, MPH ${ }^{1}$; Zohreh Ganjparvar, MA ${ }^{1}$; Batool Mousavi, MD, MPH ${ }^{{ }^{*}}$ \\ 'Janbazan Medical and Engineering Research Center (JMERC), Tehran, Iran
}

\begin{abstract}
Background: Limited studies have reported epidemiologic data on the impact of Iran-Iraq war. This study examines the war casualties for both combatants and civilians on Iranians at national level.

Methods: Databases of Veterans and Martyrs Affair Foundation (VMAF), Janbazan Medical and Engineering Research Center (JMERC) and Ministry of Health were used to collect the data. The prevalence of injuries for both civilians and combatants was presented. Casualties were studied based on conventional and unconventional weapons attacks (1980-2018), separately. Results: The Iran-Iraq war led to 183623 lost lives, 554990 injured and 40240 captured. The mean length of captivity was 45.7 months (1 month-19 years) and 2.7\% $(n=575)$ died in captivity. There were 1439180 war related injuries recorded in databanks, mostly affecting men (98.4\%). About 1439180 injuries were recorded, most of them related to conventional weapons (938928 [65.24\%]). Remaining artillery and mortar fragmentation in the body $(39.5 \%, \mathrm{n}=371236)$, psychological disorders $(15.9 \%, \mathrm{n}=$ $228944)$, and exposure to chemical weapons $(11 \%, \mathrm{n}=158817)$ were the most prevalent war-related injuries.

Conclusion: Human casualties of the Iran-Iraq war on the Iranian side and the health care system are huge even after more than three decades.

Keywords: Casualties, Chemical warfare agents, Health, Weapons of mass destruction

Cite this article as: Soroush M, Ganjparvar Z, Mousavi B. Human casualties and war: results of a national epidemiologic survey in Iran. Arch Iran Med. 2020;23(4 suppl 1):S33-S37. doi:10.34172/aim.2020.s7.
\end{abstract}

Received: May 12, 2019, Accepted: March 11, 2020, ePublished: April 1, 2020

\section{Introduction}

War is one of the most influencing factors on human health. Lasting from 1980-1988, the Iran - Iraq war was the longest (conventional) war of the $20^{\text {th }}$ century. This war that engaged $1200 \mathrm{~km}^{2}$ of the western and south-western borders of Iran, led to death and injury of hundreds of thousands of people and billions of dollars in cost. The World health organization (WHO) expects wars to be in the $8^{\text {th }}$ place in burden of disease and disability-adjusted life year (DALY) in 2020. ${ }^{1}$

There have been various reports on casualties due to the Iraq war against Iran. This study was designed because of the discrepancies between data reported in different studies and the need to obtain inclusive statistics on the injuries of the war on Iranians. The purpose of this study was to investigate the epidemiological status of Iranian war casualties more than three decades after the war.

\section{Materials and Methods}

This descriptive study examines the consequences and casualties resulting from the Iran-Iraq war. It investigates first the human casualties of conventional/unconventional weapon attacks and the damages of unexploded ordnance and landmines planted during the eight years of the war and after that until 2018. History of chemical warfare attacks and the resulting injuries, including the types of chemical warfare agents, as well as injuries or complications are to be covered next.

Information on war-related injuries was extracted from the Veterans and Martyrs Affair Foundation (VMAF). VMAF regularly provides long-term care services to the war survivors called "Janbaz" and their families by maintaining excellence in health care services through professional collaboration. The foundation is responsible for salaries and pensions, as well as insurance and rehabilitation. It also has duties regarding occupation, social-cultural and leisure services, and providing nursing home services for those in need. The total budget of the foundation in 2019 was about $\$ 3$ billion.

This foundation is the legal authority that provides pension and health services to Janbazan and civilians living with war disabilities. According to the executive regulations, the various disabilities in each survivor have to be registered in the databank of the VMAF. The injuries or disabilities (both physically or mentally) are confirmed by the special medical commission of the VMAF. Eventually, the cases are referred to the Bureau of Medical Commission's Center for investigation and supervision to confirm any further complications associated with the war casualties. ${ }^{2}$ Survivors are examined by a specialized medical team to 
determine the injuries as well as the severity of disability. VMAF records and updates all war-related injuries. War injury conditions include the presentation of a certificate of injury due to presence in combat zones as well as missile attack/landmines and explosive remnants of war (ERW) in rural and urban areas.

Databases of the VMAF, Janbazan Medical and Engineering Research Center (JMERC) and relevant databases from national studies ${ }^{2-11}$ were used to update the data. This paper presents related data in casualties caused using conventional and unconventional weapons for the first time on the Iranian side at national level.

\section{Results}

Eight years of Iran-Iraq war led to 183,623 deaths, 2,3 most of them in men $(97.1 \%)$ with a mean age of 22.8 \pm 9.04 (median $=20$ ) years ranging from 0 through 104 years. Nearly $3.5 \%$ of war-related deaths happened after the war due to complications in survivors, implanted landmines or unexploded ordnances. ${ }^{2}$ About 554990 were wounded, mostly with multiple injuries. In addition to the combatants, civilians and citizens including women and children were wounded due to conventional missiles, ${ }^{4}$ landmines ${ }^{5,6}$ and even unconventional missiles-chemical bombs. $^{3}$

There were 1439180 war-related injuries, with the majority of records registered for men (98.4\%, $\mathrm{n}=$ 1416989) in the VMAF databank, and 2093 types of physical and mental injuries. During the war, 40240 combatants or civilians were captured by Iraqi forces, consisting of $39142(99.4 \%)$ males and $24(0.06 \%)$ females. After the ceasefire in 1988 when prisoners of war (POWs) were exchanged, 39164 (97.3\%) were released and returned home, while 575 (2.7\%) had died in captivity. The mean length of captivity was 45.7 months, ranging between 1 month and 19 years.

In the third week of the war, Iraq attacked the civilian and residential areas, starting with Dezfoul. Most of the civilian mortality happened in the cities of Tehran and Dezfoul. Consequently, 2312 civilians were killed and an additional 11625 were injured. ${ }^{4}$ Therefore, this war's sphere was not limited to military personal and battle fields but extended to civilians, as well.

Although 30 years has passed since the end of the war and despite better awareness about the dangers of landmines and ERW, the remaining ordnances and landmines are still threating the health of people in five border provinces and have led to loss of many lives and serious physical and psychological problems. ${ }^{5,10,11}$ A total of 12 to 16 million landmines were planted during the war in an area of 42 million $\mathrm{km}^{2}$ in western and south-western regions of Iran: West Azerbaijan, Kurdestan, Kermanshah, Ilam and Khuzestan provinces. These landmines still remain. During and after the war, civilians in these provinces including farmers, shepherds, children and even demining personals have been in danger. The problems caused by ERW and landmines in these regions have continued after the war and still take lives or injure people in border areas. ${ }^{11}$ Between 1988 to 2003, about 4000 people have been injured by ERW and landmines, most of them civilians and almost half of them children and adolescents. About $40 \%$ of victims underwent amputation of one or more limbs and the most common injuries were reported in lower limbs. ${ }^{5,11}$

\section{Conventional Weapon Injuries}

Three decades after the war, many lives were lost and many were injured directly or indirectly. About 1,439,180 injuries were recorded, most of which were related to conventional weapons $(938928,65.24 \%)$. As Table 1 shows, the most common injuries due to conventional weapons in war survivors are related to artillery and mortar fragmentation in body $(39.5 \%, \mathrm{n}=371236)$, followed by limbs $(15.5 \%$, $\mathrm{n}=145833)$ and face $(13.8 \%, \mathrm{n}=129443)$ injuries. The injuries due to fragmentation of artillery and mortar in body most commonly affected the upper or lower limbs $(52.0 \%, \mathrm{n}=192955)$, head $(10.5 \%, \mathrm{n}=39124)$ and spine $(5.6 \%, \mathrm{n}=20702)$, respectively. The rate of amputation in upper and lower limbs was similar, while the rate of upper limbs injuries $(\mathrm{n}=115306)$ was 1.48 times higher than lower limbs $(\mathrm{n}=77649)$.

The prevalence of spinal cord injuries was $2.9 \%$ ( $\mathrm{n}=$ 42388 ) which accounted for $40.9 \%$ of the head and CNS injuries. Lumbar injuries were the most prevalent form of spinal cord injury $(89.7 \%, \mathrm{n}=38009)$. Hearing loss $(66.5 \%, \mathrm{n}=85232)$ was the most common ear, nose and throat (ENT) injury.

\section{Chemical Attack Injuries}

Despite international agreements, Iraq used chemical warfare agents including sulfur mustard and nerve agents for five years not only against military forces, but also against civilians (1983-1988). ${ }^{7}$ The first UN Fact Finding Mission analysed probable chemically contaminated samples in 1984 and declared in 2003 that 54000 bombs, 27000 short range missiles and 19500 chemical bombs were used against Iran. It also stated that Iraq used 1800 tonnes of sulfur mustard, 140 tonnes of Tabun and 600 tonnes of Sarin. ${ }^{8}$ Overall, 387 chemical attacks occurred, and 30 cities were targeted. The use of sulfur mustard was more extensive than nerve agents. Sulfur mustard, a persistent weapon, remains on the ground for months and contaminates other soldier's clothing and equipment. This beside, primary symptoms including blisters/ burnings and causing chronic complications due to exposure to sulfur mustard led to more use of this agent. The most severe sulfur mustard attacks against civilians happened in Sardasht and Oshnavieh. Two villages in West Azerbaijan province (Zardeh and Nesar Direh) were heavily attacked by nerve agents. ${ }^{3,9}$ Hospitals were 
Table 1. Prevalence of War Casualties in the Survivors of Iran-Iraq War

\begin{tabular}{|c|c|c|c|c|c|c|c|}
\hline \multirow{2}{*}{\multicolumn{2}{|c|}{ Type of Injury }} & \multicolumn{2}{|c|}{ Male } & \multicolumn{2}{|c|}{ Female } & \multicolumn{2}{|c|}{ Total } \\
\hline & & Number & $\%$ & Number & $\%$ & Number & $\%$ \\
\hline \multicolumn{2}{|c|}{ I. Conventional weapons } & 923671 & 65.19 & 15257 & 68.75 & 938928 & 65.24 \\
\hline \multicolumn{2}{|c|}{ Upper and lower limb injuries } & 143197 & 10.11 & 2636 & 11.88 & 145833 & 10.13 \\
\hline \multirow[t]{3}{*}{-} & Amputation & 25792 & 1.82 & 558 & 2.51 & 26350 & 1.83 \\
\hline & - Upper limb & 12662 & 0.89 & 264 & 1.19 & 12926 & 0.90 \\
\hline & $\circ \quad$ Lower limb & 13130 & 0.93 & 294 & 1.32 & 13424 & 0.93 \\
\hline \multicolumn{2}{|c|}{ Skin lesions } & 64820 & 4.57 & 1915 & 8.63 & 66735 & 4.64 \\
\hline \multicolumn{2}{|c|}{ Eye lesions } & 24404 & 1.72 & 609 & 2.74 & 25013 & 1.74 \\
\hline- & Unilateral or bilateral blindness & 6982 & 0.49 & 223 & 1.00 & 7205 & 0.50 \\
\hline- & Other eye injuries & 17422 & 1.23 & 386 & 1.74 & 17808 & 1.24 \\
\hline \multicolumn{2}{|c|}{ Thorax injuries } & 31739 & 2.24 & 465 & 2.10 & 32204 & 2.24 \\
\hline \multicolumn{2}{|c|}{ Abdominal injuries } & 62095 & 4.38 & 1331 & 5.99 & 63426 & 4.41 \\
\hline \multicolumn{2}{|c|}{ Face-ENT injuries } & 128054 & 9.04 & 1389 & 6.26 & 129443 & 8.99 \\
\hline \multicolumn{2}{|c|}{ Head and CNS injuries } & 103632 & 7.31 & 1406 & 6.34 & 105038 & 7.30 \\
\hline \multicolumn{2}{|c|}{ Artillery and mortar fragmentation in body } & 365730 & 25.81 & 5506 & 24.81 & 371236 & 25.79 \\
\hline \multicolumn{2}{|c|}{ II. Chemical agents injuries } & 155921 & 11.00 & 2896 & 13.05 & 158817 & 11.03 \\
\hline- & Skin lesions & 44989 & 3.17 & 848 & 3.82 & 45837 & 3.18 \\
\hline- & Eye lesions & 48496 & 3.42 & 845 & 3.81 & 49341 & 3.43 \\
\hline- & Lung lesions & 62377 & 4.40 & 1203 & 5.42 & 63580 & 4.42 \\
\hline- & Other injuries & 59 & 0.0 & - & - & 59 & 0.0 \\
\hline \multicolumn{8}{|c|}{ III. Both conventional and chemical weapons } \\
\hline- & Psychological Disorders & 225183 & 15.89 & 3761 & 16.95 & 228944 & 15.91 \\
\hline \multicolumn{2}{|c|}{ IV. POWs injuries } & 99435 & 7.02 & 49 & 0.22 & 99484 & 6.91 \\
\hline \multicolumn{2}{|c|}{ V. Uncategorized } & 12779 & 0.90 & 228 & 1.03 & 13007 & 0.90 \\
\hline \multicolumn{2}{|c|}{ Total injuries } & 1416989 & 100 & 22191 & 100 & 1439180 & 100 \\
\hline
\end{tabular}

ENT: Ear, Nose and Throat; CNS: central nervous system; POW: prisoners of war.

not safe from attacks, as well; Fateme Zahra and Soomar, the two medical establishments and field hospitals, were chemically attacked. The biggest problem resulting from chemical attacks on hospitals was impossibility of further use or reconstruction of those facilities. While hospitals were generally rebuilt after conventional attacks, these were no more utilizable after chemical attacks and were demolished.?

About 100000 were evacuated from the contaminated areas and received basic emergency medical care. One of the reliable databanks about chemical warfare attacks is the evidence recorded by the Ministry of Health and Medical Education (MOHME). Based on MOHME evidence, about 28000 hospitalizations have been registered after exposure to chemical agents; this is only part of the data on those injured by chemical warfare, as we did not have access to all 100000 records of evacuation from contaminated areas. Figure 1 shows the distribution of survivors exposed to chemical warfare who were evacuated from frontline during the Iran-Iraq war (1983-1988), and those hospitalized in field hospitals to receive emergency health care services at the time of chemical attacks.

The VMAF database classifies the data related to the injuries caused by chemical weapons based on the involved organs and the severity of late complications, from the time of injuries through 30 years after exposure. The diagnosis of the injuries and severity of the lesions in lung, skin, and eye were determined by a panel of medical experts. Expert panel members include pulmonologists, psychiatrists, neurologists, ophthalmologists, dermatologists, cardiologists, forensic medicine experts and nephrologists. The expert panel members investigate the victim's documents case by case and record the chemical injury associated complications continuously. The records of complications due to exposure were categorized based on the involved organs (lung, eye and skin). In this study, we categorized the complications according to the medical commission of the expert physicians and the VMAF guidelines. Currently, 64190 survivors suffer from complications caused by exposure to chemical agents. The number of chronic complications in this group was 158817 . About $40.1 \%$ were lung, $31.1 \%$ eye and $28.8 \%$ skin injuries (Table 1). The number of chemical injuries are higher compared to the previously published data. ${ }^{3}$

\section{Mental Disorders}

About $15.9 \%$ of injuries were mental and psychological. The prevalence of mental disorders might be as high as $40.2 \%$ in the survivors, if we consider one psychological disorder for each person injured. The diagnosis of 


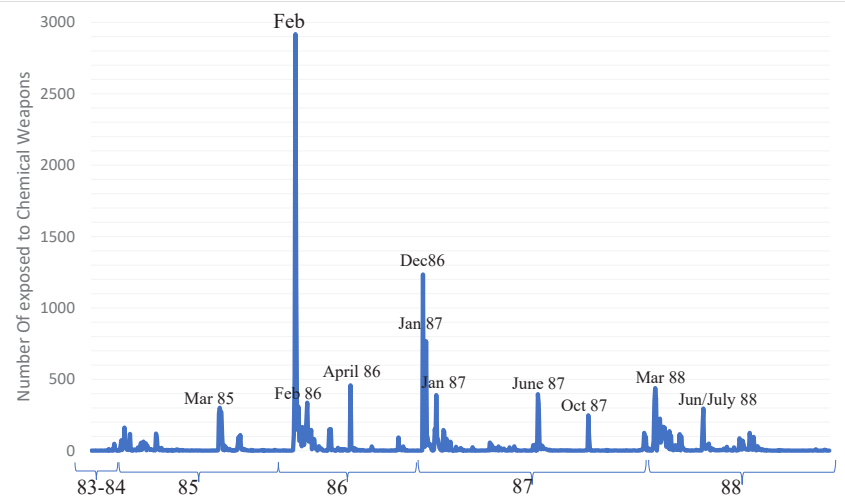

Figure 1. Distribution of Veterans Exposed to Chemical Warfare Who Were Evacuated from Frontline Based on MOHME Database $(n=28000)$ During the Iran-Iraq War (1983-1988).

psychological disorders was not correctly recorded in $61.9 \%(n=141755)$ of the disorders. In cases where the type of psychological disorders was recorded, posttraumatic stress disorder $(68.7 \%, \mathrm{n}=59875)$ was found to be the most common diagnosis.

\section{Discussion and Research Gap}

We updated the previous studies' statistics and the human casualties of Iran-Iraq war in this survey. ${ }^{1,3}$ Missile attacks caused many casualties in military forces and civilians; however, no information has been published on military and civilian zones and the resulting casualties. Though the authors had access to credible databases, the recorded data needs to be investigated and updated periodically for the survivors as well as their family members. Not only the Janbazs themselves suffer from war injuries, but also their families are harmed because of the long-term caregiving which is very costly. ${ }^{12}$ Due to the necessity of electronic medical records for veterans in Comprehensive Services Act, registering and following up the precise information on war victims will be possible in the future.

Several studies have addressed landmines and ERW and there is a national database in this field. ${ }^{5,10,11}$ The databank has been prepared before 2008. Updating and fixing the incomplete database of victims of landmines and ERW will provide more accurate information in the future.

During the war about four million were involved in the war zone, and one eighth of them were injured; these are the population who registered in the VMAF to receive health services and pension. So, the great majority of them left without follow-up, and this population might have suffered from non-physical and indirect impacts of the war which have a great burden for the health system. The health problems of this population who are out of reach are in a state of uncertainty. Accordingly, this research reveals part of the iceberg of these problems. Research focusing on this group needs to be undertaken to assess the extent and severity of their physical and mental health problems - for example; the population who were exposed to chemical weapons but were not registered.
There are populations who have been exposed to chemical warfare but did not develop acute manifestation during the war and are not considered as exposed survivors by VMAF. So, 36 years after the chemical attacks, there are still some who might have developed nonspecific clinical manifestations and complications due to chemical warfare agents in the late phase. The health problems of this group are less diagnosed as they are not referred to experts or qualified doctors. Moreover, no accurate data is available on some other exposed individuals who have no clinical symptoms. Therefore, the number of registered victims differs from the real number of exposed individuals and the rate might change in the future. Since these people who suffered from war casualties (not all those exposed to chemical warfare) are under support of the VMAF, it is estimated that the number of registered chemical weapons victims in the VMAF database is far smaller than people who were exposed. There are two types of veterans exposed to chemical weapons registered in VMAF. The first type pertains to those who have primary documents about their treatment at the time of exposure (1984-1988). The second group members manifest symptoms of chronic complications resulting from exposure to chemical warfare without any documents from the war period confirmed by relevant authorities (trusted expert physicians). ${ }^{3}$ Some of non-registered exposed individuals might have clinical or subclinical manifestations related to exposure to chemical agents. One of the most important subject that needs to be addressed is the population exposed to nerve agents. There has not been a comprehensive study on the health status of this group. The reason for receiving little attention could be related to the higher rate of SM exposed survivors (nearly twenty times higher) versus those injured by nerve agents.

The effect of traumatic head/brain injuries is still unclear, as there is a huge gap in research regarding how extensive the problem is and how to address it. Evidence suggests a high prevalence of war-related injuries, with increasing concern about the incidence of depression. Unlike the physical injuries of war, these situations are commonly 
unrevealed at beginning and remain hidden to other health care workers, family members and the society. The impact often affects multiple health aspects for decades post-conflict from being in war to middle/late adulthood. Consequently, these conditions are less recognized and unappreciated. Thus, the health care system needs to meet these gaps for providing better quality health care to all in need.

Our study delivers information on the burden of health among Iranian populations who experienced prolonged war and survived while entering older adulthood. The pattern of injuries indicates the greatest suffering in the survivors. Meanwhile, limited researches investigate and document the indirect cultural, social and economic impacts including migration, internal displacement, psychological disorders, food resource limitation, and outbreak of violence and social unrests caused by the war. ${ }^{1}$ The total budget for VMAF shows a two-fold increase over the last five years (from $\$ 1.5$ billion in 2014 to $\$ 3$ billion in 2019), emphasizing the greater economic burden over the time. At the end, investigating inhumane effects of the use of conventional and especially unconventional warfare on the environment and documenting the direct and indirect impacts of wars, which have remained unclear, are among the research needs. The data of this survey was based on Iranian war-related casualties. We recommend the conduct of a similar study on the Iraqi side to make the results comparable at international level.

\section{Authors' Contribution}

MRS and BM were the principal investigators and responsible for the study design. ZG and BM collected the data, extracted records, analyzed the data and wrote the final manuscript. MRS, ZG and BM actively contributed to all elements of the study. All authors read and approved the final manuscript.

\section{Conflict of Interest Disclosures}

The author has no conflicts of interest.

\section{Ethical Statement}

The Ethics Committee of Janbazan Medical and Engineering Research Center approved the study with ethics code of 96-E-P101

\section{Acknowledgement}

We are immensely grateful to prof. Sograt Faghihzadeh (Department of Biostatistics, Zanjan University of Medical Sciences) for his comments on an earlier version of the manuscript.

\section{References}

1. Zargar $M$, Araghizadeh $H$, Soroush MR, Khaji A. Iranian casualties during the eight years of Iraq-Iran conflict. Rev Saude Publica. 2007;41(6):1065-6. doi:10.1590/s003489102007000600025

2. Taebi G, Soroush MR, Modirian E, Khateri S, Mousavi B, Ganjparvar Z, et al. Human Costs of Iraq's Chemical War
- Studies on the human casualties of the Iran-Iraq war and the prevalence of physical and mental injuries at national level have been missed in research topics.

- $\quad$ For the first time, we report the data available and registered on injuries in war survivors based on three national databases.

- Artillery and mortar fragmentation injuries, psychological disorders, and exposure to chemical weapons were found to be the most common war-related injuries registered for the survivors' health problems.

- A total of 40240 veterans or civilians were captured by Iraqi forces (from 1 month through 19 years in captivity).

- The total budget for VMAF shows a two-fold increase over the last five years, emphasizing the greater economic burden over the time.

against Iran; an Epidemiological Study. Iran J War Public Health. 2015;7(2):115-21.

3. Mousavi B, Moradi-Lakeh M, Karbakhsh M, Soroush M. Years of life lost among Iranian people killed in the Iraq-Iran war: the 25-year perspective. Int J Inj Contr Saf Promot. 2014;21(4):3827. doi: 10.1080/17457300.2013.843569.

4. Khaji A, Fallahdoost S, Soroush MR. Civilian casualties of Iranian cities by ballistic missile attacks during the Iraq-Iran war (1980-1988). Chin J Traumatol. 2010;13(2):87-90.

5. Soroush AR, Flahati F, Zargar M, Soroush MR, Araghizadeh $\mathrm{H}$, Khateri $\mathrm{S}$, et al. Injuries associated with landmines and unexploded ordnances in Iran. Arch Iran Med. 2010;12(4):384.

6. Mousavi B, Soroush MR, Masoumi M, Khateri S, Modirian E, Shokoohi H, et al. Epidemiological study of child casualties of landmines and unexploded ordnances: a national study from Iran. Prehosp Disaster Med. 2015;30(5):472-7. doi: 10.1017/ S1049023X15005105.

7. Khateri S, Ghanei M, Keshavarz S, Soroush M, Haines D. Incidence of lung, eye, and skin lesions as late complications in 34,000 Iranians with wartime exposure to mustard agent. J Occup Environ Med. 2003;45(11):1136-43. doi: 10.1097/01. jom.0000094993.20914.d1

8. United Nations Monitoring, Verification and Inspection Commission (UNMOVIC) report. Unresolved Disarmament issues, Iraq's Proscribed Weapons Programs 6 March, UNMOVIC Working document; 2003:140-145. Available from: https://www.un.org/Depts/unmovic/documents/6mar. pdf.

9. Foroutan A. Medical Experiences of Iraq's Chemical warfare. Tehran: Baqiyatallah University of Medical Sciences; 2003: 179-188.

10. Mousavi B, Soroush MR, Masoumi M, Khateri S, Modirian E, Shokoohi H. Epidemiological study of child casualties of landmines and unexploded ordnances: a national study from Iran. Prehosp Disaster Med. 2015;30(5):472-7. doi: 10.1017/ S1049023X15005105

11. Soroush AR, Falahati F, Zargar M, Soroush MR, Khateri SH, Khaji A. Amputations due to landmine and unexploded ordnances in post-war Iran. Arch Iran Med.2008; 11(6):595-7.

12. Mousavi B, Seyed Hoseini Davarani SH, Soroush M, Jamali A, Khateri S, Talebi M, et al. Quality of life in caregivers of severely disabled war survivors. Rehabil Nurs. 2015;40(3):139-47. doi: 10.1002/rnj.159. 